\title{
An intelligent agent model for learning group development in the digital learning environment: A systematic literature review
}

\author{
Budi Laksono Putro, Yusep Rosmansyah, Suhardi \\ School of Electrical Engineering and Informatics, Bandung Institute of Technology, Indonesia
}

\begin{abstract}
Article Info
Article history:

Received Aug 15, 2019

Revised Oct 29, 2019

Accepted Feb 3, 2020

Keywords:

Collaborative problem solving

Digital learning environment

Group development

Group development model

Intelligent agent

Metrics performance

ABSTRACT

Group development is the first and most important step for the success of collaborative problem solving (CPS) learning in the digital learning environment (DLE). A literacy study is needed for studies in the intelligent agent domain for group development of collaborative learning in DLE. This paper is a systematic literature review (SLR) of intelligent agents for group formation from 2001 to 2019. This paper aims to find answers to 4 (four) research questions, namely: 1) What components to develop intelligent agents for group development; 2) What is the intelligent agent model for group development; 3) How are the metrics for measuring intelligent agent performance; and 4) How is the Framework for developing intelligent agent. The components of the intelligent agent model consist of: member attributes, group attributes (group constraints), and intelligent techniques. This research refers to Srba and Bielikova's group development model. The stages of the model are formation, performing and closing. An intelligent agent model at the formation stage. A performance metric for the intelligent agent at the performance stage. The framework for developing an intelligent agent is a reference to the stages of development, component selection techniques, and performance measurement of an intelligent agent.
\end{abstract}

This is an open access article under the CC BY-SA license.

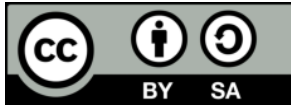

\section{Corresponding Author:}

Budi Laksono Putro,

School of Electrical Engineering and Informatics,

Bandung Institute of Technology, Bandung, Indonesia.

Email: blputro@gmail.com

\section{INTRODUCTION}

Collaborative problem solving (CPS) learning based on a digital learning environment (DLE) is an effort to realize $21^{\text {st }}$ century skills [1-5]. Group development is the first and most important step for the success of CPS learning in DLE [6-10]. A literacy study is needed for studies in the intelligent agent domain for group development of collaborative learning in DLE. This paper is a systematic literature review (SLR) of intelligent agents for group formation from 2001 to 2019. Source articles from ACM Digital Library, Science Direct, Springer Link, IEEE Xplore Digital Library, ProQuest, and EBSCOhost. The research objectives are represented in 4 research questions and the outcomes in Table 1 below. The answers to the 4 research questions above are based on the results of the processing and analysis of 26 SLR papers.

The intelligent agent component map consists of member attributes, group attributes, and intelligent techniques [7-9, 11-14]. The member attribute component represents the problem of the group member population. Components of group attribute (constraint group formation) are methods, constraints, and rules 
for group development [15]. The component of engineering intelligence represents intelligent technology to increase efficiency and effectiveness in group development [13, 16-18].

Table 1. Research question and outcome

\begin{tabular}{lll}
\hline Research question (RQ) & Outcome \\
\hline RQ1 & $\begin{array}{l}\text { What components are there for developing } \\
\text { intelligent agents for group development on }\end{array}$ & $\begin{array}{l}\text { Map of intelligent agent components for group } \\
\text { development on DLE. }\end{array}$ \\
DLE? & $\begin{array}{l}\text { Development of an intelligent agent model at } \\
\text { the group development stage? }\end{array}$ & $\begin{array}{l}\text { The intelligent agent model at the group } \\
\text { development stage }\end{array}$ \\
RQ3 & $\begin{array}{l}\text { What are the intelligent agent performance } \\
\text { metrics at the group development stage? }\end{array}$ & $\begin{array}{l}\text { Intelligent agent performance metrics for group } \\
\text { development on DLE }\end{array}$ \\
RQ4 & $\begin{array}{l}\text { What is the intelligent agent development } \\
\text { framework for group development on DLE? }\end{array}$ & $\begin{array}{l}\text { An intelligent agent development framework } \\
\text { for group development on DLE. }\end{array}$ \\
\hline
\end{tabular}

Classification of group development models based on DLE are Long-term virtual groups and Sort-term virtual groups. Long-term virtual groups begin with Tuckman's model (1965), Tuckman and Jensen's model (1977) [19], and Daradoumis et al.'s model (2002) [20, 21]. Tuckman's model is a reference for Long-term virtual groups. This model proved successful for the development of long-term learning groups (for example [22]), but was not very suitable for the development of learning groups on DLE. The characteristics of this model are to build strong relationships between group members, long term, and depend on collaborative planning.

Sort-term virtual group starts with Srba and Bielikova's model (2014) [8]. This model is for short-term groups (usually in hours). The life cycle of the model is simpler than the Long-term virtual groups. Srba and Bielikova's model (2014) in Figure 1 consists of three stages: formation, performing, and closing [8]. The formation stage is the stage for group formation. Performing stage is a measure of the effectiveness of collaborative learning processes (collaboration performance) [23, 24]. And closing stage is a review and evaluation process of groups that have was made. There has been no discussion of the framework for implementing intelligent agents at each stage of the model.

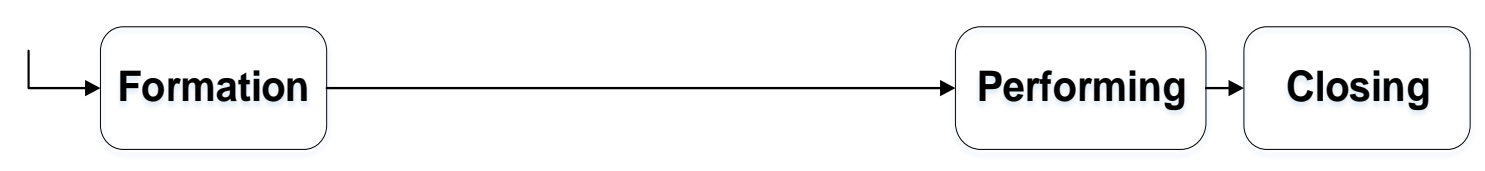

Figure 1. Srba and Bielikova's group formation model [8]

An intelligent agent for the development of study groups on DLE is classified as a virtual short-term model. This research refers to Srba\&Bielikova's group development model [8], in Figure 1. The intelligent agent model is implemented at the formation stage. The intelligent agent model consists of 3 (three) components, namely: member attributes, group attribute (constrain of group formation), and intelligent technique [7-9, 11-14]. Performance metrics for the intelligent agent at the performance stage. Performance metrics consist of 5 (five) measurements [23, 24] namely group formation time; optimization of the distribution of members in groups; Collaboration performance (CO); Knowledge; and skills.

The intelligent agent development framework is a reference to the stages of development, component selection techniques, and performance measurement of intelligent agents. The development framework consists of 5 stages, namely: 1) Understanding the problems and goals of group development; 2) Determining components for intelligent agents; 3) Development of intelligent agent software; 4) Implementation and testing, and 5) Evaluation of intelligent agents.

A detailed discussion of component mapping, intelligent agent models, performance metrics, and a framework for developing intelligent agents is discussed in chapter 3 (result and analysis). The mapping of intelligent agent components is the answer to RQ1, discussed in chapter 3.1. The intelligent agent model is the answer to RQ2, discussed in chapter 3.2. The intelligent performance metrics are the answer to RQ3, discussed in chapter 3.2. and The intelligent agent development framework is the answer to RQ4, discussed in chapter 3.3. 


\section{RESEARCH METHOD}

The research methodology aims to find answers to 4 (four) research questions. The research methodology consists of 4 stages, as follows:

1) Search for SLR articles based on research questions in Table 1

2) Related searches on intelligent agent domains for the development of collaborative learning groups in DLE

3) A correspondent with experts in the domain of intelligent agent development for group development. The paper collection is based on a search strategy based on 3 keywords and their synonyms in Table 2 . Paper searches based on Category 1, Category 2, and Category 3 keywords are combined by Boolean AND (\&) operators, and for each keyword synonym for each category use the OR (II) Boolean operator

4) Analyze search results for mapping intelligent agent components, developing intelligent agent models, performance metrics, and frameworks for developing intelligent agents

Table 2. Categories of keywords and their synonyms

\begin{tabular}{ll}
\hline Category and synonyms & Search string \\
\hline Group formation (Category 1). Synonyms: & (Group formation \| group development \| group \\
(group formation, group development, group creation, & creation \| group design \| group composition $\|$ \\
group design, group composition, team formation, & team formation, team development $\|$ team \\
team development, team creation, team design, & creation \| team design \| team composition) \\
team composition). & $\&$ \\
Collaborative learning (Category 2). Synonyms: & (Collaborative learning \| collaborative problem \\
(collaborative learning, collaborative problem solving, & solving \| csgf \| cscl \| group learning $\|$ team \\
csgf, cscl, group learning, team learning) & learning) \\
Intelligent (Category 3). Synonyms: & $\&$ \\
(intelligent, smart, adaptive, algorithms, methods, & (Intelligent \| smart \| adaptive $\|$ algorithms $\|$ \\
technique) & methods \| technique). \\
\hline
\end{tabular}

\section{RESULTS AND DISCUSSION}

This chapter discusses the mapping of intelligent agent components, intelligent agent models, performance metrics, and the framework for developing intelligent agents. The mapping of intelligent agent components is discussed in chapter 3.1, the intelligent agent model is discussed in chapter 3.2, performance metrics are discussed in chapter 3.2, and the framework for developing intelligent agents is discussed in chapter 3.3 .

\subsection{Intelligent agent component mapping}

The SLR results of intelligent agent research for group development from 2001 to 2019 are illustrated in Table 3. Search results included 111 articles from the ACM Digital Library, 170 articles from Science Direct, 387 articles from Springer Link, 318 articles from IEEE Xplore Digital Library, 312 articles from ProQuest, and 311 articles from EBSCOhost. There are 26 papers that are relevant for mapping intelligent agent components. The mapping of intelligent agent components is based on the column mapping in table 3. Component maps include member attributes, group attributes, and intelligent techniques [7-9, 11-14].

The member attribute component represents the problem of the population of group members and the purpose of group development. Components of group attribute/(constraint group formation) are methods, constraints, and rules for group development [15]. The intelligent technique component represents intelligent technology to increase efficiency and effectiveness in group development [13, 16-18].

The population of Member attribute components consists of 4 articles of knowledge competence, 6 articles of learning style, 3 articles of social interaction, 3 articles of team roles, 4 articles of personal traits, and 14 articles of various attributes. Table 3 shows many alternative methods of group formation, and each alternative method has advantages and disadvantages. Each method refers to the problem of the population of group members and the purpose of group development [9].

The intelligent technique component for group development consists of 18 different algorithms. The algorithm most widely used in group development is the genetic algorithm. The level of intelligence utilizing intelligent technology includes: 1) automatic level, 2) smart level, and 3) intelligent level. Automatic Level is an attempt to automate the process of group formation. Smart level is a higher level than automatic level. At this level machines have started the process of decision making, and there is still an element 
of human intervention. The intelligent level is the highest level. The decision making process is completely taken over by the machine.

Table 3. SLR of intelligent agent research for group development from 2001 to 2019

\begin{tabular}{|c|c|c|c|c|c|c|c|c|c|}
\hline \multirow{2}{*}{ No } & \multirow{2}{*}{ Ref } & \multicolumn{6}{|c|}{ Member attribute (MA) } & \multirow{2}{*}{$\begin{array}{l}\text { Intelligent } \\
\text { technique }\end{array}$} & \multirow{2}{*}{ Group attribute (constrain group formation) } \\
\hline & & Other & MAK & MAL & MAS & MAT & MAP & & \\
\hline 1 & [25] & & & $\sqrt{ }$ & & & & $\mathrm{D}$ and $\mathrm{E}$ & Data mining methods: clustering learning style. \\
\hline 2 & [26] & Various & & & & & & G & AHC method, which is known as SLG. \\
\hline 3 & [27] & Various & & & & & & $\mathrm{D}$ & Dynamically forming groups on the MCSCL system \\
\hline 4 & [28] & Various & & & & & & A & $\begin{array}{l}\text { The inversion method to determine the representation } \\
\text { of dominant attributes in group members. }\end{array}$ \\
\hline 5 & [29] & Various & & & & & & A & $\begin{array}{l}\text { Comparison between intra-heterogeneous and Inter- } \\
\text { homogeneous groups with } 3 \text { different algorithms. }\end{array}$ \\
\hline 6 & {$[30]$} & Various & & & & & & A & $\begin{array}{l}\text { Formulate various group goals based on various } \\
\text { problems forming groups. Method by comparing } 3 \\
\text { algorithms (exhaustive, proposed method, and } \\
\text { random) }\end{array}$ \\
\hline 7 & [31] & Various & & & & & & $\mathrm{K}$ & $\begin{array}{l}\text { Formation of groups based on attributes desired by } \\
\text { teachers. }\end{array}$ \\
\hline 8 & [32] & Informal data & & & & & & K & $\begin{array}{l}\text { Automatic group formation model. Using data } \\
\text { mining methods, namely: unification, mining, and } \\
\text { drawing conclusions. }\end{array}$ \\
\hline 9 & [33] & Thinking styles & & & & & & $\mathrm{K}$ & Apply the psychological attributes of students. \\
\hline 10 & [34] & Various & & & & & & F & $\begin{array}{l}\text { Minimize the time taken by the teacher to create } \\
\text { groups }\end{array}$ \\
\hline 11 & [35] & Programming styles & & & & & & $\mathrm{K}$ & Use attribute programming style for group formation. \\
\hline 12 & [36] & Empty slot attribute & & & & & & $\mathrm{C}$ & Use the empty slot method in group formation. \\
\hline 13 & [37] & Dynamic attribute & & & & & & $\mathrm{O}$ & $\begin{array}{l}\text { Method of forming groups dynamically on a web } \\
\text { learning system. }\end{array}$ \\
\hline 14 & [38] & $\begin{array}{l}\text { Characteristics \& } \\
\text { functions of learner }\end{array}$ & & & & & & $\mathrm{O}$ & $\begin{array}{l}\text { Group formation pays attention to individual learning } \\
\text { patterns and collaborative learning. }\end{array}$ \\
\hline 15 & [39] & Various & & & & & & $\mathrm{O}$ & $\begin{array}{l}\text { Formation of groups based on rules and policies in } \\
\text { the I-MINDS system. }\end{array}$ \\
\hline 16 & {$[40]$} & $\mathrm{X}$ & & $\sqrt{ }$ & & & $\sqrt{ }$ & B & $\begin{array}{l}\text { Heterogeneous groups method, by comparing } 3 \\
\text { different algorithms. }\end{array}$ \\
\hline 17 & [41] & $\mathrm{X}$ & & $\sqrt{ }$ & & & & A, C & $\begin{array}{l}\text { Methods for forming heterogeneous, homogeneous, } \\
\text { and mixed groups. }\end{array}$ \\
\hline 18 & {$[42]$} & $\mathrm{X}$ & $\sqrt{ }$ & $\sqrt{ }$ & $\sqrt{ }$ & & & A & $\begin{array}{l}\text { Formation of groups is based on collecting attributes } \\
\text { from OSN }\end{array}$ \\
\hline 19 & [43] & $\mathrm{X}$ & $\sqrt{ }$ & $\sqrt{ }$ & $\sqrt{ }$ & & & B & $\begin{array}{l}\text { The method of utilizing the student feature model } \\
\text { becomes the attribute model. }\end{array}$ \\
\hline 20 & [44] & $\mathrm{X}$ & $\sqrt{ }$ & $\sqrt{ }$ & & & & E & $\begin{array}{l}\text { Homogeneous and heterogeneous group formation } \\
\text { methods are based on the number of groups the } \\
\text { instructors want. }\end{array}$ \\
\hline 21 & {$[45]$} & $\mathrm{X}$ & & & & $\sqrt{ }$ & & $\mathrm{O}$ & $\begin{array}{l}\text { Formation of a balanced group using the evolution } \\
\text { algorithm, based on the role of members } \\
\text { automatically. }\end{array}$ \\
\hline 22 & [46] & $X$ & & & & $\sqrt{ }$ & & $\mathrm{O}$ & $\begin{array}{l}\text { Belbin's team role method, by way of agreement with } \\
\text { the team role. }\end{array}$ \\
\hline 23 & [47] & $X$ & & & $\sqrt{ }$ & $\sqrt{ }$ & $\sqrt{ }$ & $\mathrm{R}$ & $\begin{array}{l}\text { The framework for group formation is based on } \\
\text { teacher preferences. }\end{array}$ \\
\hline 24 & [48] & $\mathrm{X}$ & $\sqrt{ }$ & & & & $\sqrt{ }$ & $\mathrm{K}$ & Method of measuring heterogeneous groups. \\
\hline 25 & {$[22]$} & $\mathrm{X}$ & & & & & $\sqrt{ }$ & $\mathrm{R}$ & $\begin{array}{l}\text { Formation of groups based on continuous } \\
\text { improvement of rules. }\end{array}$ \\
\hline \multirow[t]{2}{*}{26} & [49] & Various & & & & & & & Computer-aided group formation. \\
\hline & 26 & 14 & 4 & 6 & 3 & 3 & 4 & 18 variety & \\
\hline
\end{tabular}

Note.

MAK = Member Attribute - Knowledge Competance. MAL = Member Attribute - Learning Style. MAS = Member Attribute - Social Interaction. MAT = Member Attribute - Team Role. MAR = Member Attribute - Personal Traits.

A : Genetic algorithm (5), B: Particle swarm optimization (3), C:Greedy algorithm (2), D: K-means (2), E: Fuzzy C-Means (FCM) (2), F: Rule-based system (1), G: agglomerative hierarchical clustering (AHC) (1), H: Ant Colony algorithm (1), I: Tabu search (1), J: Mashup Technique (1), K: Random Mutation Hill Climbing (1), L: Quality metrics of Software (1), M: Integration base on Ontology (1), N: Means End Analysis (1), O: Multi-agents (2), P: Knowledge base evolutionary algorithm (1), Q: Semantic Web Ontologies (1), R: Regression analysis optimization (1).

\subsection{Intelligent agent model}

The intelligent agent model is developed based on the intelligent agent component map. The intelligent agent model consists of 3 (three) components, namely: member attributes, group attributes, and intelligent technique. The intelligent agent model is illustrated in Figure 2. The intelligent agent model is at the formation stage of the Srba and Bielikova's group development model [8]. This model aims to find the most optimal components for developing intelligent agent software for group development. The performance of intelligent agent software for group development is measured at the performing stage. Evaluation and improvement of intelligent agent software are carried out at the closing stage. 


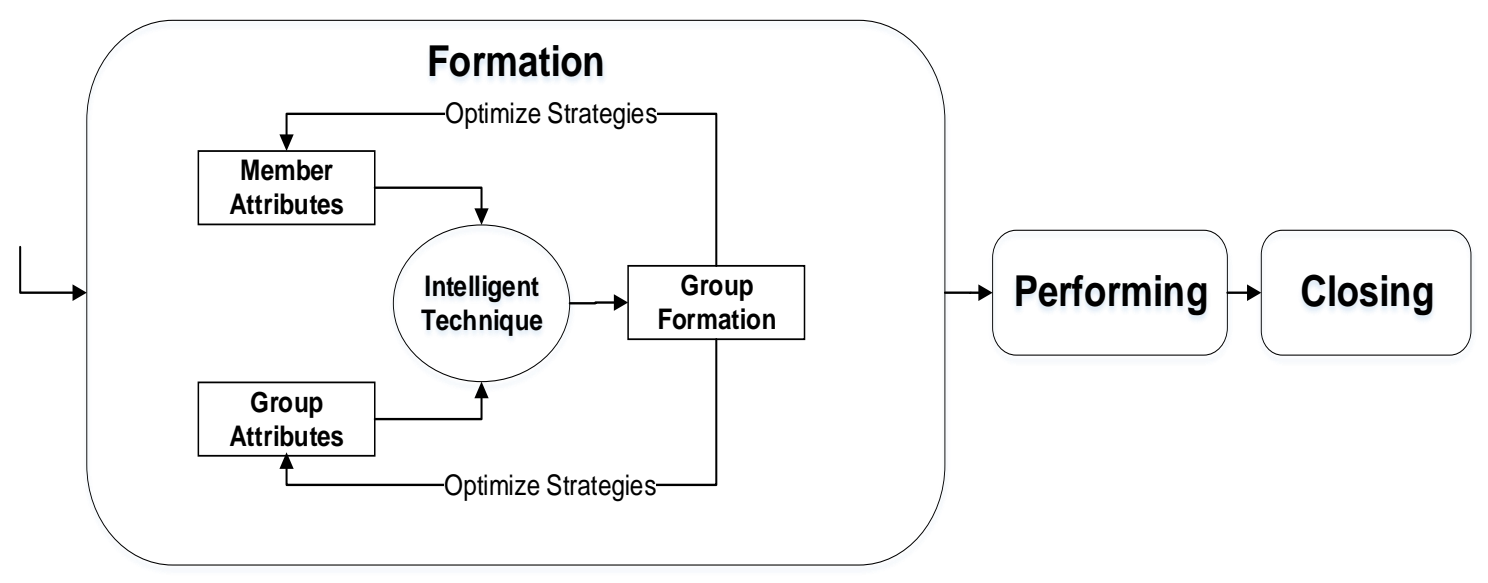

Figure 2. An intelligent agent model at the stage of the Srba and Bielikova's group development model [8]

The performance of intelligent agents is measured at the Performing stage. Metrics for measuring intelligent agent performance are described in Table 4. Intelligent performance metrics are based on 5 (five) measuring tools namely [23, 24]: Group formation time, optimizing the distribution of members in groups, Collaboration performance (CO), Knowledge, and skill.

Table 4. Metrics Performance of intelligent agent

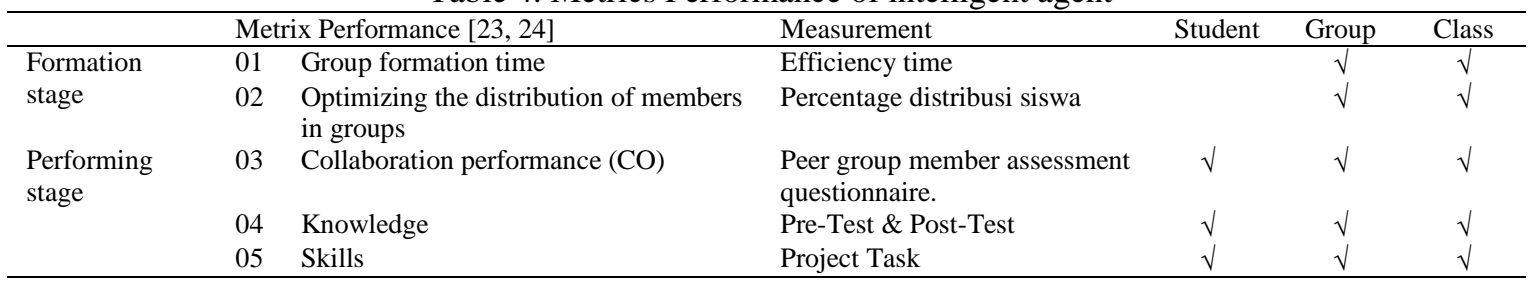

\subsection{An intelligent agent development framework}

The intelligent agent development framework is a reference to the stages of intelligent agent development, and the most appropriate component selection technique. The intelligent agent development framework is illustrated in Figure 3 below. The intelligent agent development framework consists of 5 stages, as follows:

1. Understanding the problems and goals of group development. The initial step is understanding the problem of the existing group member population. The goal is the best hypothesis for several solutions to solve the problem. The output of this stage is defining the problem and setting goals for developing an intelligent agent software.

2. Determining components for intelligent agents. Understanding the problem and the goal of developing intelligent greatly influences the quality of the selection of intelligent components. The intelligent component map is depicted in table 3, which consists of member attributes, group attributes, and intelligent technique. The output of this stage is the selection of components for intelligent agents.

3. Development of intelligent agent software. This stage is the implementation of stages 1 and 2 into an intelligent agent software. The output of this stage is an intelligent agent software for group development.

4. Implementation and testing. Implementation and testing of intelligent agent software on research objects for group development. The output of this stage is the data from the implementation and testing of intelligent agent software.

5. Evaluation of intelligent agents. Evaluation is the result of the analysis of the implementation and testing data at the 4th stage. The output of this stage is the improvement of intelligent agent software for group development. 


$\left.\left.\left.\begin{array}{|c}\text { 1. Understanding the } \\ \text { problems and goals of } \\ \text { group development. }\end{array} \quad \begin{array}{c}\text { 2. Determining } \\ \text { components for } \\ \text { intelligent } \\ \text { agents. }\end{array} \quad \begin{array}{c}\text { 3. Development } \\ \text { of intelligent } \\ \text { agent software. }\end{array}\right\rangle \begin{array}{c}\text { Implementation } \\ \text { and testing. }\end{array}\right\rangle \begin{array}{c}\text { 4. } \\ \text { intelligent } \\ \text { agents }\end{array}\right\rangle$

Figure 3. Framework for developing intelligent agents for group formation

The framework in Figure 3 is made for reference to the development of intelligent agents for group development. Many alternative methods for developing intelligent agents and each alternative development method has advantages and disadvantages [50]. This study summarizes 26 different intelligent agents (Table 3) for group development with problems and the application of each method. The method of developing intelligent agents is influenced by the problems of the member population, the purpose of group development, the selection of component attributes of intelligent, and measuring the effectiveness of intelligent agents. Each population group has special problem characteristics. Understanding group member population problems is an initial, important, and influential step to the success of the next stage. The choice of intelligent component attributes is strongly influenced by the characteristics of the group population problem and the purpose of group development. The choice of measuring the effectiveness of an intelligent agent is also strongly influenced by the previous stages. The development of intelligent agents is still open for further research. Intelligent testing also still requires more effective measurement methods and a wider population.

\section{CONCLUSION}

An intelligent agent for the development of study groups on DLE is classified as a virtual short-term model. This research refers to Srba and Bielikova's group development model. The stages of the model are formation, performing, and closing. The intelligent agent model is implemented at the formation stage. Performance metrics are performed at the performance stage. Evaluation of intelligent agents is carried out at the closing stage. The intelligent agent model consists of 3 components, namely member attribute, group attribute (constrain group formation), and an intelligent technique. Performance metrics for intelligent agents consist of 5 (five) measuring instruments, namely group formation time; optimization of the distribution of members in groups; Collaboration performance (CO); Knowledge; and skills. The framework for implementing intelligent agents is a reference to the stages of development, component selection techniques, and performance measurement of intelligent agents. Research on the intelligent agent domain still has opportunities to be developed. The results of this study are expected to be intelligent development references for group development.

\section{ACKNOWLEDGEMENTS}

Praise Allah for all the blessings that He has given. Thanks also to our parents, wives, children, and friends for their participation and support. Thank you to the Indonesia Endowment Fund for Education (LPDP), for the BUDI-DN scholarship.

\section{REFERENCES}

[1] P. Griffin and E. Care, "Assessment and teaching of 21st century skills," Br. J. Educ. Technol., vol. 46, no. 4, pp. E15-E16, 2015.

[2] J. Khlaisang and N. Songkram, "Designing a virtual learning environment system for teaching twenty-first century skills to higher education students in ASEAN," Technol. Knowl. Learn., vol. 24, no. 1, pp. 41-63, 2019.

[3] R. Pathi, G. V. Rao, P. Rama Krishna, and P. Bharath Kumar, "Development of a modular unit of a higher level framework or tool for basic programming course teaching through E-learning mode," TELKOMNIKA Telecommunication Computing Electronics and Control, vol. 16, no. 6, pp. 2828-2834, 2018.

[4] Y. Rosmansyah, A. Z. R. Langi, and U. P. Indonesia, "Selection of learning materials b ased on students" behaviors in 3DMUVLE," vol. 16, no. 5, pp. 2127-2136, 2018.

[5] R. E. Saputro, S. Salam, M. H. Zakaria, and T. Anwar, "A gamification framework to enhance students' intrinsic motivation on MOOC," TELKOMNIKA Telecommunication Computing Electronics and Control, vol. 17, no. 1, pp. 170-178, 2019.

[6] S. Isotani, A. Inaba, M. Ikeda, and R. Mizoguchi, "An ontology engineering approach to the realization of theory-driven group formation," Int. J. Comput. Collab. Learn., vol. 4, no. 4, pp. 445-478, 2009.

[7] N. Maqtary, A. Mohsen, and K. Bechkoum, "Group formation techniques in computer-supported collaborative learning: A systematic literature review," Technol. Knowl. Learn., vol. 24, no. 2, pp. 169-190, 2019.

[8] I. Srba and M. Bielikova, "Dynamic group formation as an approach to collaborative learning support," IEEE Trans. Learn. Technol., vol. 8, no. 2, pp. 173-186, 2015. 
[9] R. C. D. Reis, S. Isotani, C. L. Rodriguez, K. T. Lyra, P. A. Jaques, and I. I. Bittencourt, "Affective states in computer-supported collaborative learning: Studying the past to drive the future," Comput. Educ., vol. 120, pp. 29-50, 2018.

[10] A. A. von Davier, J. Hao, L. Liu, and P. Kyllonen, "Interdisciplinary research agenda in support of assessment of collaborative problem solving: Lessons learned from developing a collaborative science assessment prototype," Comput. Human Behav., vol. 76, pp. 631-640, 2017.

[11] H. Sadeghi and A. A. Kardan, "A novel justice-based linear model for optimal learner group formation in computer-supported collaborative learning environments," Comput. Human Behav., vol. 48, pp. 436-447, 2015.

[12] B. L. Putro, Y. Rosmansyah, and Suhardi, "Group formation in smart learning environment : A literature review," Int. Conf. on Inf. Tech. Systems and Innovation (ICITSI), pp. 381-385, 2018.

[13] N. J. A. Amit Kumar, Ninni Singh, "Learning styles based adaptive intelligent tutoring systems: Document analysis of articles published between 2001. and 2016," International Journal of Cognitive Research in Science, Engineering and Education, vol. 5, pp. 83-98, 2017.

[14] A. Acharya and D. Sinha, "A 'mixed' strategy for collaborative group formation and its learning outcomes," $J$. Educ. Technol. Syst., vol. 46, no. 4, pp. 440-462, 2018.

[15] I. Srba, "Collaboration support by groups creation in educational domain," Inf. Sci. Technol. Bull. ACM Slovakia, vol. 4, no. 2, pp. 62-64, 2012

[16] S. Isotani et al., "A semantic web-based authoring tool to facilitate the planning of collaborative learning scenarios compliant with learning theories," Comput. Educ., vol. 63, pp. 267-284, 2013.

[17] A. Asselman, A. E. Nasseh, and S. Aammou, "Survey of intelligent collaborative E-learning systems," 5th International Conference on Emerging eLearning Technologies and Applications (ICETA), pp. 1-7, 2017.

[18] A. K. I. Magnisalis and S. Demetriadis, "Adaptive and intelligent systems for collaborative learning support: A review of the field," IEEE Trans. Learn. Technol., vol. 4, no. 1, pp. 5-20, 2011.

[19] B. W. Tuckman and M. A. C. Jensen, "Stages of small-group development," Gr. Org. Manag., vol. 2, no. 4, pp. 419-427, 1977.

[20] T. Daradoumis, M. Guitert,F. Giménez, J. M. Marquès, and T. Lloret, "Supporting the composition of effective virtual groups for collaborative learning," The International Conference on Computers in Education, Proceedings, pp. 332-336, 2002.

[21] Giménez, Guitert, Daradoumis, Marquès, and Lloret, "Cooperative learning \& working in a virtual environment : A case study," in Proc. 2nd Eur. Distance Edu. Netw., Res. Policy Open Distance Learning, pp. 228-233, 2002.

[22] A. Mujkanovic, D. Lowe, K. Willey, and C. Guet, "Unsupervised learning algorithm for adaptive group formation: Collaborative learning support in remotely accessible laboratories," International conference on information society (i-Society), pp. 50-57, 2012.

[23] A. Ounnas, D. E. Millard, and H. C. Davis, "A metrics framework for evaluating group formation," International ACM Conference on Supporting group work, Proceedings, pp. 221-224, 2007.

[24] I. Wu and W. Chen, "Evaluating the e-learning platform from the perspective of knowledge management: The AHP approach," J. Libr. Inf. Stud., vol. 11, no. 1, pp. 1-24, 2013.

[25] S. Lailiyah, E. Yulsilviana, and R. Andrea, "Clustering analysis of learning style on Anggana High School student," TELKOMNIKA Telecommunication Computing Electronics and Control, vol. 17, no. 3, pp. 1409-1416, 2019.

[26] A. Triayudi and I. Fitri, "A new agglomerative hierarchical clustering to model student activity in online learning," TELKOMNIKA Telecommunication Computing Electronics and Control, vol. 17, no. 3, pp. 1226-1235, 2019.

[27] S. Amara, J. Macedo, F. Bendella, and A. Santos, "Group formation in mobile computer supported collaborative learning contexts: A systematic literature review,” J. Educ. Technol. Soc. vol. 19, no. 2, pp. 258-273, 2015.

[28] M. M. B. Jozan and F. Taghiyareh, "An evolutionary algorithm for homogeneous grouping to enhance web-based collaborative learning," Int. J. Comput. Sci. Res. Appl., vol. 3, no. 1, pp. 74-85, 2013.

[29] S. P. Tseng, M. W. Huang, H. J. Liu, C. C. Chung, and C. M. Chiu, "A virtual reality based training system for cultural tourism," Advances in Web-Based Learning-ICWL 2013 Workshops, vol. 8390, 2015.

[30] J. Moreno, D. A. Ovalle, and R. M. Vicari, "A genetic algorithm approach for group formation in collaborative learning considering multiple student characteristics," Comput. Educ., vol. 58, no. 1, pp. 560-569, 2012.

[31] Roland Hubscher, "Assigning students to groups using general and assigning students to groups using general and context-specific criteria," IEEE Trans. Learn. Technol., vol. 3, no. 3, pp. 178-189, 2010.

[32] N. Rubens, M. Vilenius, and T. Okamoto, "Automatic group formation for informal collaborative learning," IEEE/WIC/ACM Int. Conf. Web Intell. Intell. Agent Technol., vol. 3, pp. 231-234, 2009.

[33] D. Y. Wang, S. S. J. Lin, and C. T. Sun, "DIANA: A computer-supported heterogeneous grouping system for teachers to conduct successful small learning groups," Comput. Human Behav., vol. 23, no. 4, pp. 1997-2010, 2007.

[34] R. L. de F. Carlos Miguel Tobar, "A support tool for student group definition," Pap. Present. 37th ASEE/IEEE Front. Educ. Conf., pp. 7-8, 2007.

[35] E. S. J. de Faria, J. M. Adán-Coello, and K. Yamanaka, "Forming groups for collaborative learning in introductory computer programming courses based on students' programming styles: An empirical study," ASEE/IEEE Frontiers in Education Conference, pp. 6-11, 2006.

[36] M. A. Redmond, "A computer program to aid assignment of student project groups," ACM SIGCSE Bull., vol. 33, no. 1, pp. 134-138, 2001.

[37] M. Wessner and H.-R. Pfister, "Group formation in computer-supported collaborative learning," International ACM SIGGROUP Conference on Supporting Group Work, Proceedings, pp. 24-31, 2001.

[38] M. Ikeda, S. Go, and R. Mizoguchi, "Opportunistic group formation," Artificial Intelligence and Education, Proceedings of AIED, pp. 167-174, 1997. 
[39] L. Soh, N. Khandaker, and A. Hall, "Forming and scaffolding human coalitions with a multi-agent framework," 6th international joint conference on autonomous agents and multiagent systems, Proceedings, vol. 5, pp. 406-408, 2007.

[40] Z. Zheng and N. Pinkwart, "A discrete particle swarm optimization approach to compose heterogeneous learning groups,” IEEE 14th Int. Conf. Adv. Learn. Technol., no. 2, pp. 49-51, 2014.

[41] S. Abnar, F. Orooji, and F. Taghiyareh, "An evolutionary algorithm for forming mixed groups of learners in web based collaborative learning environments," IEEE Int. Conf. on Tech. Enhanced Education (ICTEE), pp. 1-6, 2012.

[42] S. Brauer and T. C. Schmidt, "Group formation in elearning-enabled online social networks," 15th International Conference on Interactive Collaborative Learning (ICL), pp. 1-8, 2012.

[43] T. F. Ho, J. S. Shyong, F. H. Wang, and C. T. J. Li, "Composing high-heterogeneous and high-interaction groups in collaborative learning with particle swarm optimization," WRI World Congr. Comput. Sci. Inf. Eng. CSIE, vol. 4, pp. 607-611, 2009.

[44] C. E. Christodoulopoulos and K. A. Papanikolaou, "A group formation tool in a e-Learning context," Int. Conf. Tools with Artif. Intell. ICTAI-Proceedings, vol. 2, pp. 117-123, 2007.

[45] V. D. Yannibelli and A. Amandi, "Forming well-balanced collaborative learning teams according to the roles of their members: An evolutionary approach," 12th IEEE International Symposium on Computational Intelligence and Informatics, CINTI-Proceedings, pp. 265-270, 2011.

[46] V. Yannibelli and A. Amandi, "A deterministic crowding evolutionary algorithm to form learning teams in a collaborative learning context," Expert Syst. Appl., vol. 39, no. 10, pp. 8584-8592, 2012.

[47] A. Ounnas, H. Davis, and D. Millard, "A framework for semantic group formation in education," Educ. Technol. Soc., vol. 12, no. 2009, pp. 34-38, 2009.

[48] S. Graf and R. Bekele, "Forming heterogeneous groups for intelligent collaborative learning systems with ant colony optimization," 8th International Conference, Intelligent Tutoring System, pp. 217-226, 2006.

[49] S. Mirzaei and A. F. Hayati, "Effects of the computer mediated communication interaction on vocabulary improvement," TELKOMNIKA Telecommunication Computing Electronics and Control, vol. 16, no. 5, pp. 2217-2225, 2018.

[50] S.-T. Shen, S. D. Prior, A. S. White, and M. Karamanoglu, "Using personality type differences to form engineering design teams," Eng. Educ., vol. 2, no. 2, pp. 54-66, 2007.

\section{BIOGRAPHIES OF AUTHORS}
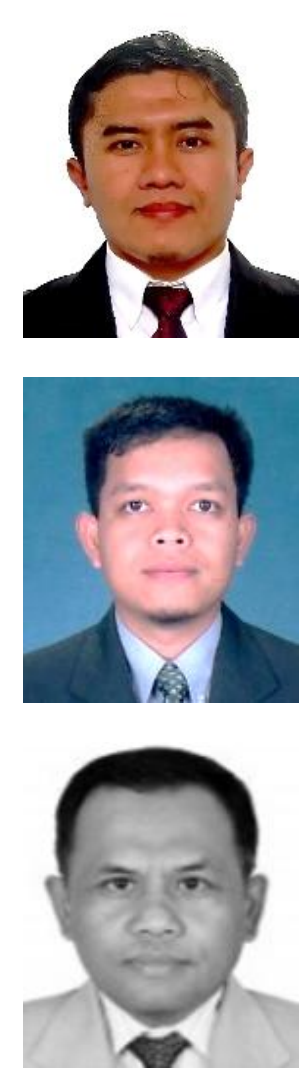

Budi Laksono Putro received his bachelor degree in computer science from Universitas Padjadjaran, Bandung, Indonesia, in 2002, and his master degree at the School of Electrical Engineering and Informatics (STEI), ITB, Bandung, Indonesia, in 2010. He is currently working toward a doctoral degree at the School of Electrical Engineering and Informatics, ITB. He works for Indonesia University of Education in the Computer Science Education field. He is currently a member of the Services Computing Research Group (SCRG) of SEEI ITB. His current research interest includes mobile learning technologies, service computing, software engineering, and information systems.

Yusep Rosmansyah received the B.S. degree from Bandung Institute of Technology, Indonesia, in 1993, and both the M.Sc. and Ph.D. degrees from the University of Surrey, U.K. He has been a researcher and an associate professor at the School of Electrical Engineering and Informatics, Bandung Institute of Technology (SEEI ITB), Indonesia. His current research interest includes mobile learning technologies and cyber security.

Suhardi received the bachelor degree in electrical engineering from the Bandung Institute of Technology, Bandung, Indonesia, in 1988, the master degree in management from Parahyangan Catholic University, Bandung, Indonesia, in 2012, and the Doctor of Engineering degree in telecommunication engineering from the Technical University of Berlin, Berlin, Germany, in 1997. He is currently an Associate Professor with the School of Electrical Engineering and Informatics, SEEI ITB. He is the Head of Services Computing Research Group (SCRG), SEEI ITB. His research interests include service computing, IT value and risk, service systems engineering, information and social networks, information and social networks, information governance and management, and internet society and law. 